\title{
Terapia fotodinâmica como coadjuvante no tratamento da halitose de origem bucal: revisão narrativa de literatura
}

Photodynamic therapy as a coadjutant in the treatment of halitosis of oral origin: narrative literature review

La terapia fotodinámica como coadyuvante en el tratamiento de la halitosis oral: una revisión narrativa de la literatura

Isaac Müller de Sousa Maia ORCID: https://orcid.org/0000-0002-7044-661X Universidade Potiguar, Brasil

E-mail: isaacmuller123@gmail.com
Daniel Felipe da Silva Sales ORCID: https://orcid.org/0000-0001-6827-2393 Universidade Potiguar, Brasil E-mail: daniellfelipe.com@gmail.com

Amanda Barbosa de Godoy ORCID: https://orcid.org/0000-0002-8798-9725 Universidade Potiguar, Brasil E-mail: amandagodoy99@gmail.com

Fabiano Florêncio Alves ORCID: https://orcid.org/0000-0001-9725-0337 Universidade Potiguar, Brasil

E-mail: fabianoflorencioalves@gmail.com

Anayla Oliveira da Silva

ORCID: https://orcid.org/0000-0002-8112-1650 Universidade Potiguar, Brasil

E-mail: anaylasilva@hotmail.com

Maria Luisa Faria Barroso

ORCID: https://orcid.org/0000-0002-2818-6594 Universidade Potiguar, Brasil

E-mail: luisafariaa@outlook.com

Danielle Azevedo Rodrigues Machado Rangel ORCID: https://orcid.org/0000-0001-8446-2605 Universidade Potiguar, Brasil

E-mail: danielleazevedomachado@ hotmail.com

Maria Cecília Azevedo de Aguiar

ORCID: https://orcid.org/0000-0002-1229-4486 Universidade Federal do Rio Grande do Norte, Brasil

E-mail: mariaceciliaaguiar@gmail.com

Diana Rosado Lopes Fernandes

ORCID: https://orcid.org/0000-0002-0422-1885 Universidade Potiguar, Brasil

E-mail: dianarosadolopes@hotmail.com

\begin{abstract}
Resumo
A halitose, popularmente conhecida como mau hálito, é um termo utilizado para descrever odores desagradáveis oriundos da cavidade bucal, independentemente de sua causa. Estudos atuais vêm abordando que a Terapia Fotodinâmica Antimicrobiana (aPDT) tem sido utilizada como coadjuvante no tratamento dessa patologia. O objetivo geral deste estudo é revisar a literatura sobre a eficácia da terapia fotodinâmica no tratamento da halitose de origem bucal e o objetivo específico é revisar a literatura sobre a ação da terapia fotodinâmica no tratamento da halitose de origem bucal. Foi realizada uma revisão narrativa de literatura e o levantamento de estudos foi realizado nas bases de dados PubMed, Biblioteca Virtual em Saúde e periódicos CAPES, com os descritores "Halitose"; "Fotoquimioterapia"; "Terapia Fotodinâmica"; "Terapêutica" e "Cavidade Oral". Os artigos foram publicados entre os anos de 2017 e 2021, nos idiomas inglês, português e espanhol. Após isso, 24 artigos foram incluídos nesta revisão. A ideia da realização deste estudo surgiu primeiramente pela grande parcela da população com halitose, que interfere diretamente na qualidade de vida. A aPDT é uma opção para diminuir a quantidade de microrganismos presentes na boca e baseia-se na combinação de uma fonte de luz de comprimento de onda adequado com um fotossensibilizador e
\end{abstract}


o oxigênio do ambiente. A aPDT mostrou-se eficaz na redução do sulfeto de hidrogênio imediatamente após sua aplicação, reduzindo a halitose de origem bucal em um curto período de tempo.

Palavras-chave: Halitose; Fotoquimioterapia; Terapia Fotodinâmica; Terapêutica; Cavidade Oral.

\begin{abstract}
Halitosis, popularly known as bad breath, is a term used to describe unpleasant odors from the oral cavity, regardless of its cause. Current studies have approached that Antimicrobial Photodynamic Therapy (aPDT) has been used as an adjunct in the treatment of this pathology. The general objective of this study is to review the literature on the efficacy of photodynamic therapy in the treatment of oral halitosis and the specific objective is to review the literature on the action of photodynamic therapy in the treatment of oral halitosis. A narrative literature review was carried out and the survey of studies was carried out in the PubMed, Virtual Health Library and CAPES journals databases, with the descriptors "Halitosis"; "Photochemotherapy"; "Photodynamic Therapy"; "Therapeutics" and "Oral Cavity". The articles were published between 2017 and 2021, in English, Portuguese and Spanish. After that, 24 articles were included in this review. The idea of carrying out this study first came from the large portion of the population with halitosis, which directly interferes with quality of life. aPDT is an option to reduce the amount of microorganisms present in the mouth and is based on the combination of a light source of adequate wavelength with a photosensitizer and oxygen from the environment. aPDT proved to be effective in reducing hydrogen sulfide immediately after its application, reducing oral halitosis in a short period of time.
\end{abstract}

Keywords: Halitosis; Photochemotherapy; Photodynamic Therapy; Therapy; Oral Cavity.

\title{
Resumen
}

La halitosis, conocida popularmente como mal aliento, es un término que se utiliza para describir los olores desagradables de la cavidad bucal, independientemente de su causa. Los estudios actuales se han acercado a que la Terapia Fotodinámica Antimicrobiana (aPDT) se ha utilizado como coadyuvante en el tratamiento de esta patología. El objetivo general de este estudio es revisar la literatura sobre la eficacia de la terapia fotodinámica en el tratamiento de la halitosis oral y el objetivo específico es revisar la literatura sobre la acción de la terapia fotodinámica en el tratamiento de la halitosis oral. Se realizó una revisión narrativa de la literatura y se realizó la encuesta de estudios en las bases de datos de revistas PubMed, Virtual Health Library y CAPES, con los descriptores "Halitosis"; "Fotoquimioterapia"; "Terapia fotodinámica"; "Terapéutica" y "Cavidad bucal". Los artículos fueron publicados entre 2017 y 2021, en inglés, portugués y español. Posteriormente, se incluyeron 24 artículos en esta revisión. La idea de realizar este estudio surgió primero de la gran parte de la población con halitosis, que interfiere directamente en la calidad de vida. El aPDT es una opción para reducir la cantidad de microorganismos presentes en la boca y se basa en la combinación de una fuente de luz de longitud de onda adecuada con un fotosensibilizador y oxígeno del ambiente. El aPDT demostró ser efectivo para reducir el sulfuro de hidrógeno inmediatamente después de su aplicación, reduciendo la halitosis oral en un corto período de tiempo.

Palabras clave: Halitosis; Fotoquimioterapia; Terapia Fotodinámica; Terapia; Cavidad Oral.

\section{Introdução}

A halitose, popularmente conhecida como mau hálito, é um termo utilizado para descrever odores desagradáveis oriundos da cavidade bucal, independentemente da sua causa. Além disso, é considerada um problema de saúde que causa impacto negativo na qualidade de vida.

A cavidade bucal é um sistema complexo que apresenta um grande número de superfícies biológicas, secreções e nutrientes que fornecem um habitat favorável para mais de 700 espécies microbianas. Isso, juntamente com condições que favorecem a retenção de biofilme, como prótese e aparelhos ortodônticos, aliados com uma higiene bucal deficiente, contribui fortemente com o desenvolvimento da halitose (Kellesarian et al., 2017).

Segundo Du et al. (2019), o tratamento da halitose é o terceiro principal motivo pelo qual os pacientes procuram o consultório odontológico. De acordo com Silva et al. (2018), estima-se que 38,1\% da população geral apresenta halitose. Segundo Ciarcia et al. (2019), cerca de 90\% dos casos apresentam como fator etiológico a boca, uma vez que, as bactérias anaeróbias gram negativas, ao realizarem a degradação proteolítica de substratos como restos de comida, sangue e células epiteliais, liberam compostos de enxofre voláteis responsáveis pelo odor fétido.

Atualmente o tratamento da halitose é realizado por meio da remoção mecânica e química do biofilme com raspadores de língua, escovas de dente e bochechos. Estudos atuais vêm abordando que a Terapia Fotodinâmica Antimicrobiana (aPDT) tem sido utilizada como coadjuvante no tratamento dessa patologia (Gonçalves et al., 2017). 
Ciarcia et al. (2019) abordam em seu trabalho que para a halitose, condição cuja principal causa são as bactérias anaeróbias, a aPDT obteve resultados positivos aliada ao azul de metileno como fotossensibilizador, levando à redução do sulfeto de hidrogênio e da carga bacteriana no dorso da língua.

A ideia da realização deste estudo surgiu primeiramente pela grande parcela (aproximadamente $38,1 \%$ ) da população com halitose, que interfere diretamente na qualidade de vida e que na maioria das vezes é de origem bucal. Além disso, a literatura traz a terapia fotodinâmica com um procedimento simples e de baixo custo, que pode ajudar em diversas terapêuticas na odontologia. Dessa forma, é extremamente importante abordar esse tema, pois contribuirá para a agregação de mais informações sobre o conteúdo, além de incentivar a discussão acerca desse assunto.

O objetivo geral deste estudo é revisar a literatura sobre a eficácia da terapia fotodinâmica no tratamento da halitose de origem bucal, e o objetivo específico é revisar a literatura sobre a ação da terapia fotodinâmica no tratamento da halitose de origem bucal.

\section{Metodologia}

O presente estudo trata-se de uma revisão narrativa de literatura do tipo qualitativa (Pereira et al., 2018), levando-se em consideração a pergunta: “A terapia fotodinâmica colabora para o tratamento da halitose?”. O levantamento de estudos foi realizado nas bases de dados National Library of Medicine National Institutes of Health (PubMed), Biblioteca Virtual em Saúde (BVS) e Portal de periódicos CAPES. Foi utilizada a seguinte combinação dos descritores: "Halitose"; "Fotoquimioterapia"; "Terapia fotodinâmica"; "Terapêutica" e "Cavidade Oral", além dos operadores booleanos em língua inglesa "OR" e "AND". Além disso, uma pesquisa manual foi desenvolvida por meio da análise das listas de referências dos artigos com potencial de inclusão na presente revisão narrativa.

Para inclusão, alguns critérios foram estabelecidos, tais como: ano de publicação (2017 a 2021), idioma, sendo selecionados estudos publicados nos idiomas inglês, português e espanhol e também artigos que abordassem sobre o tratamento da halitose por meio da terapia fotodinâmica. Foram excluídos artigos que não atendiam aos critérios descritos anteriormente. As duplicatas foram removidas após a identificação. Trabalhos publicados em inglês e espanhol foram traduzidos para avaliação posterior. A busca pelos estudos, representada na Figura 1, resultou na inclusão de 24 artigos. 
Figura 1: Fluxograma de coleta de estudos.

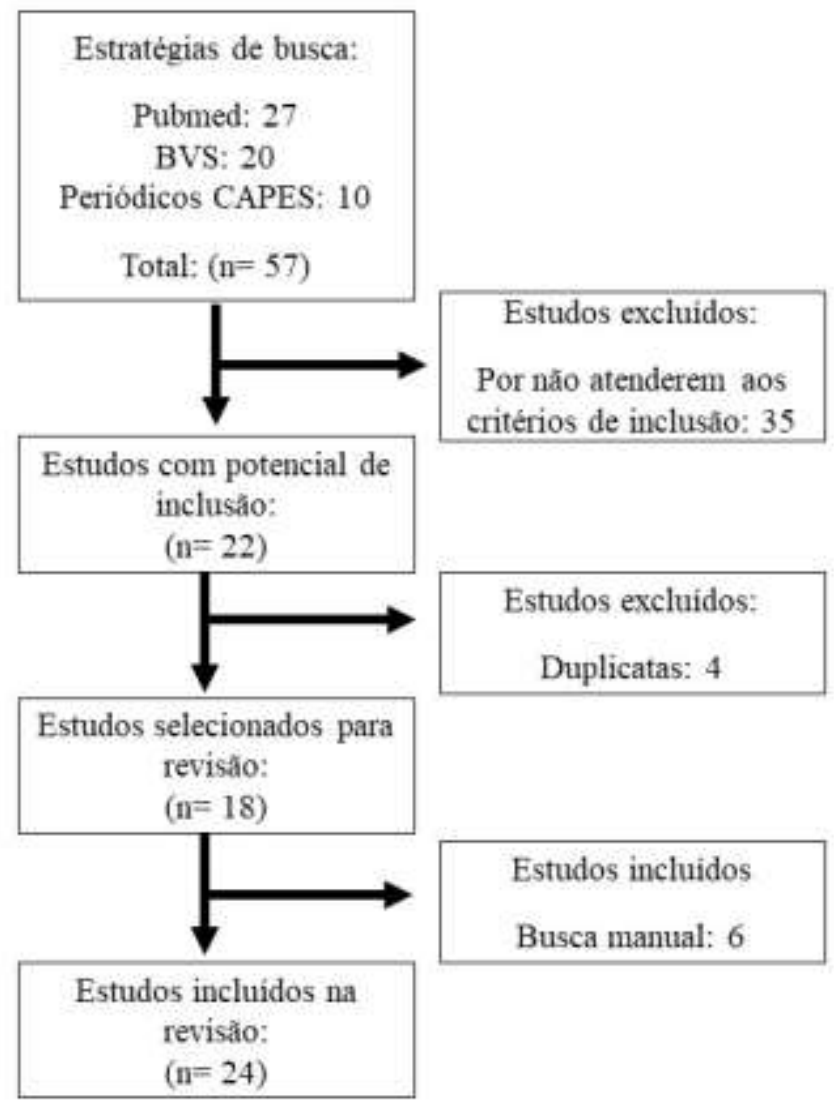

Fonte: Dados dos autores (2021)

Na Figura 1, está descrito todo o processo de coleta de estudos, desde a estratégia de busca nas bases de dados selecionadas, até o número total de artigos incluídos após a aplicação dos critérios de inclusão e exclusão.

\section{Resultados e Discussão}

A busca resultou ao todo na inclusão de 24 artigos. Os estudos selecionados foram interpretados, sintetizados e compilados a partir dos objetivos deste trabalho. A apresentação dos artigos está disposta no Quadro 1. 
Quadro 1: Artigos incluídos na revisão.

\begin{tabular}{|c|c|c|c|c|c|}
\hline AUTOR & ANO & TIPO DE ESTUDO & AUTOR & ANO & TIPO DE ESTUDO \\
\hline AGUIAR et al & 2017 & Estudo seccional & MYLONA et al & 2020 & Revisão sistemática \\
\hline BICAK & 2018 & Revisão de literatura & MUBAYRIK et al & 2017 & Estudo transversal \\
\hline $\begin{array}{l}\text { COSTACURTA } \\
\text { et al }\end{array}$ & 2020 & $\begin{array}{l}\text { Ensaio clínico } \\
\text { randomizado }\end{array}$ & NAGRAJ et al & 2019 & Revisão de literatura \\
\hline $\begin{array}{c}\text { DA MOTA } \\
\text { CIARCIA et al }\end{array}$ & 2019 & $\begin{array}{l}\text { Ensaio clínico } \\
\text { randomizado e } \\
\text { controlado } \\
\end{array}$ & PATIL et al & 2017 & Ensaio clínico randomizado \\
\hline DO VALE et al & 2021 & $\begin{array}{l}\text { Ensaio clínico } \\
\text { randomizado e } \\
\text { controlado } \\
\end{array}$ & RENVERT et al & 2020 & Revisão de consenso \\
\hline DO VALE et al & 2019 & $\begin{array}{l}\text { Protocolo para um } \\
\text { ensaio clínico } \\
\text { randomizado e } \\
\text { controlado. }\end{array}$ & $\begin{array}{l}\text { RICCI DONATO et } \\
\text { al }\end{array}$ & 2017 & Ensaio clínico \\
\hline DU et al & 2019 & Pesquisa clínica & ROMERO et al & & $\begin{array}{c}\text { Um ensaio clínico } \\
\text { randomizado, controlado e } \\
\text { cego. }\end{array}$ \\
\hline GIAFFERIS et al & 2017 & Revisão de literatura & $\begin{array}{l}\text { SEERANGAIYAN; } \\
\text { JÜCH; WINKE }\end{array}$ & 2018 & Revisão de literatura \\
\hline $\begin{array}{l}\text { GONÇALVES et } \\
\text { al }\end{array}$ & 2017 & Ensaio clínico & SILVA et al & 2018 & $\begin{array}{c}\text { Revisão sistemática e análise } \\
\text { de meta-regressão }\end{array}$ \\
\hline $\begin{array}{l}\text { HAMPELSKA et } \\
\text { al }\end{array}$ & 2020 & Revisão de literatura & $\begin{array}{l}\text { TUNGARE; } \\
\text { ZAFAR; } \\
\text { PARANJPE }\end{array}$ & 2018 & Revisão de literatura \\
\hline $\begin{array}{l}\text { KELLESARIAN } \\
\text { et al }\end{array}$ & 2017 & $\begin{array}{l}\text { Revisão sistemática e } \\
\text { meta-análise }\end{array}$ & VELOSO et al & 2020 & Ensaio in vitro \\
\hline KOLBE \& SILVA & 2017 & Revisão de literatura & WANG & 2017 & Ensaio clínico randomizado \\
\hline
\end{tabular}

Fonte: Dados dos autores (2021).

No Quadro 1, encontram-se os artigos selecionados para inclusão no presente trabalho. Nele está descrito os autores em ordem alfabética, ano de publicação, tema do trabalho e o tipo de estudo.

\subsection{Halitose}

Segundo Tungare, Zafar e Paranjpe (2021), a origem da palavra halitose vem da junção do latim halitus (respiração) e do grego osis (processo patológico). É utilizada para caracterizar qualquer odor desagradável de ar expirado, independentemente de sua origem (Nagaraj et al., 2019).

Costacurta et al. (2020) definem a halitose como presença de hálito fétido, percebido tanto pelo próprio paciente quanto pelos demais indivíduos com quem ele interage. Já para Renvert et al. (2020) é definida como um nível de odor no hálito que é socialmente inaceitável. Para Aguiar et al. (2017), trata-se de uma alteração na qualidade do odor do ar exalado durante a respiração pela boca ou narinas, e pode variar desde processos fisiológicos e adaptativos até alterações patológicas.

Para Tungare, Zafar e Paranjpe (2021) a halitose pode ser classificada em delirante e genuína. A primeira refere-se ao tipo de halitose relacionada à imaginação, onde o paciente relata possuir a condição, porém outras pessoas não sentem o odor característico, inclusive o cirurgião dentista (CD). Já o tipo genuína pode se dividir em fisiológica e patológica, nas quais podem ser de origem intra ou extraoral. 


\subsubsection{Prevalência da halitose}

Apesar de diversos estudos abordarem a prevalência estimada de halitose, a maioria não especifica a origem da halitose em questão (Renvert et al., 2020) e isso ocorre, principalmente, pela falta de padronização no diagnóstico (Ciarcia et al., 2019). Entretanto, as estimativas relatadas na literatura sugerem que a prevalência da halitose, independente da sua origem, é cerca de $30 \%$.

Silva et al. (2018) publicaram uma revisão sistemática e meta-análise e concluíram que a prevalência estimada da halitose é de 31,8\%. Além disso, tal condição apresentou uma incidência 2 vezes maior entre indivíduos do sexo masculino quando comparado ao feminino, independentemente da idade. Os autores também abordaram que em países desenvolvidos, a prevalência é de $29 \%$, enquanto em países de renda média baixa é de $39,8 \%$.

Tais índices podem estar relacionados com os determinantes sociais de saúde dos países incluídos na revisão, tendo em vista que a falta de acesso à saúde e educação, colaboram com as altas taxas desta condição.

\subsubsection{Etiologia e fisiopatologia da halitose}

Apesar da etiologia da halitose ser multifatorial, envolvendo órgãos como cavidade bucal, estômago e pulmões, aproximadamente $90 \%$ dos casos da halitose genuína tem etiologia bucal, mediante condições patológicas, como gengivite, periodontite e fatores comumente presentes na língua, a exemplo do biofilme lingual (Ciarcia et al., 2019; Seerangaiyan, Jüch \& Winke, 2018).

Mubayrik et al. (2017) abordaram em seu trabalho que a halitose de origem bucal pode ser causada por fatores extra ou intraorais, dentre eles o uso de alguns tipos de medicamentos, boca seca, tabagismo, alterações sistêmicas e uma pobre higiene oral.

Veloso et al. (2020) afirmaram que 85\% dos pacientes apresentam a ação de bactérias gram negativas como causa da halitose de origem bucal. Isso se deve ao fato de a anatomia bucal ser bastante complexa, apresentando diversos locais onde bactérias podem agregar-se e formar colônias, favorecendo assim a produção de compostos de enxofre voláteis.

$\mathrm{Na}$ halitose de origem bucal há presença de compostos de enxofre voláteis, como sulfeto de hidrogênio, sulfeto de dimetila, dissulfeto de dimetila e metil mercaptano, que são produzidos em sua maioria por bactérias anaeróbias gram negativas (Hampelska et al., 2020). Bicak (2018) afirma que a formação dos compostos de enxofres voláteis pode ser afetada pela secreção de saliva, diminuição de oxigênio e metabolismo bacteriano.

Além disso, outro fator que está diretamente relacionado com a formação da halitose é a hipossalivação, levando em consideração que a ocorrência da diminuição do fluxo salivar gera uma mudança da flora bacteriana bucal para microrganismos gram negativos, principais responsáveis pela formação do mau odor (Kolbe \& Silva, 2017). Ademais, uma redução na saturação de oxigênio da saliva resulta em uma diminuição do $\mathrm{pH}$ da mesma, formando e liberando diaminas, resultando também em odor fétido (Tungare, Zafar \& Paranjpe, 2021).

Outra classificação derivada da halitose genuína é a halitose fisiológica, que ocorre ao acordar, causada principalmente pela redução na produção e liberação da saliva pelas glândulas salivares maiores e menores. Essa hipossalivação irá impedir a ação da saliva na limpeza das superfícies intraorais, causando assim o crescimento de bactérias anaeróbias que irão degradar partículas de alimentos aprisionadas e células epiteliais descamadas da língua, originando o odor fétido que emana da boca (Tungare; Zafar \& Paranjpe, 2021).

É importante pontuarmos que a halitose fisiológica se trata de um mecanismo natural e não deve ser utilizada como parâmetro no diagnóstico de halitose de origem bucal patológica. Além disso, essa condição afeta praticamente todos os indivíduos, mesmo que eles apresentem tecidos periodontais saudáveis, ausência de infecções e uma boa higiene bucal. 
Contudo, existe a possibilidade de risco de vieses nos estudos publicados, caso os mesmos considerem esse tipo de halitose como critério de diagnóstico.

\subsubsection{Diagnóstico da halitose de origem bucal}

De acordo com Renvert et al. (2020) o diagnóstico é de suma importância para o tratamento. Para Tungare, Zafar e Paranjpe (2021) após excluir a halitose fisiológica, é importante realizar um exame clínico intraoral completo, a fim de descobrir se existem fatores predisponentes para a halitose de origem bucal, como: lesões de cáries profundas, biofilme lingual, restos alimentares necróticos aprisionados em espaços interdentais, infecção odontogênica, próteses mal adaptadas, patologias de tecido mole ou até mesmo doenças malignas. Ciarcia et al. (2019) explicam que há diversos métodos utilizados para a realização do diagnóstico da halitose, dentre eles: o exame organoléptico, uso de monitores de sulfeto e a cromatografia gasosa.

O método organoléptico trata-se de uma avaliação clínica subjetiva, na qual um profissional treinado utiliza uma escala para quantificar o odor exalado no ar que sai do nariz e da boca, classificando-o entre 0 e 5, nos quais o grau 0: nenhum odor detectável, grau 1: odor é dificilmente detectável, grau 2: odor ligeiramente detectável, excedendo o limite do normal, grau 3: odor certamente identificável, grau 4: odor forte e grau 5: odor muito forte (Tungare, Zafar \& Paranjpe, 2021; Ciarcia et al., 2019).

Um segundo método é o uso de monitores de sulfeto, tendo em vista que esses dispositivos quantificam o valor total de compostos de enxofres voláteis liberados da cavidade bucal (Ciarcia et al., 2019). Segundo Tungare, Zafar e Paranjpe (2021) o aparelho detecta moléculas que contenham enxofre na respiração e é impossibilitado de reconhecer moléculas que não tenham este gás.

Uma terceira técnica, considerada como padrão ouro por Vale et al. (2019), é a cromatografia gasosa. Nela, utiliza-se um cromatógrafo gasoso que realiza a medição individual por meio de um medidor, de compostos de enxofres voláteis (sulfeto de hidrogênio, metil mercaptano e sulfeto de dimetil) presentes na respiração ou saliva. Para realização desta técnica é necessário a aquisição de um equipamento chamado cromatógrafo gasoso, no qual apresenta um elevado custo. Além disso, requer um treinamento especializado para seu uso.

Muitos CD optam por realizarem o diagnóstico por meio do método organoléptico, pois não requer materiais, instrumentais ou equipamentos, não implicando em custos. Porém, este teste pode gerar constrangimento tanto no paciente como no profissional, devido a maneira como é realizado. Além disso, existe a possibilidade da transmissão de doenças respiratórias, como a Sars-Cov-2, tuberculose, parotidite infecciosa, dentre outras.

\subsubsection{Tratamento da halitose de origem bucal}

O tratamento da halitose de origem bucal deve ser realizado de acordo com o seu fator etiológico (Vale et al., 2019). Patil et al. (2017) descreveram em seu estudo que o mais comum envolve o uso de enxaguantes bucais, realização de tratamento periodontal, orientação de higiene bucal e a remoção da saburra lingual. Apesar desta ser facilmente removida por meio do debridamento mecânico pelo paciente, ainda é um método pouco utilizado pelo desconforto ou por ignorância, porém é uma técnica amplamente recomendada (Wang et al., 2017).

Se a origem da halitose estiver relacionada com a hipossalivação, Giafferis (2017), aborda que existem produtos disponíveis para o tratamento desta condição. Trata-se de géis, soluções, spray e gotas adaptando-se às mais diversas necessidades dos pacientes que se queixam de boca seca. 
Alguns estudos indicam que o fluoreto de amina tem um efeito positivo na diminuição da halitose (Bicak, 2018). Além disso, terapêuticas alternativas, como aPDT vêm sendo empregadas na tentativa de regular a halitose (Ciarcia et al., 2019).

\subsection{Terapia fotodinâmica}

A aPDT é uma opção para diminuir a quantidade de microrganismos presentes na boca e baseia-se na combinação de uma fonte de luz de comprimento de onda adequado com um fotossensibilizador e o oxigênio do ambiente (Mylona et al., 2020). Com esse método, não há relatos de resistência bacteriana, não há efeitos colaterais, a microbiota bucal é preservada e a toxicidade para humanos é mínima (Gonçalves et al., 2017).

Na aPDT, geralmente são utilizados dispositivos feitos de diodo emissor de luz (LED). Donato et al. (2017) utilizaram em seu trabalho duas fontes de luzes, uma azul e outra vermelha, respectivamente nos comprimentos $450 \mathrm{~nm}$ e $630 \mathrm{~nm}$. Nos estudos de Vale et al. (2019), Labban et al. (2020) e Romero et al. (2021) os autores realizaram as irradiações com um laser de diodo vermelho de 660nm. Motta et al. (2021) utilizaram um dispositivo LED de consultório odontológico acoplado a um radiômetro, operando com 395 a 480nm.

No que se refere ao uso dos fotossensibilizantes na aPDT, Gonçalves et al. (2017), Ciarcia et al. (2019), Labban et al (2020), Romero et al. (2021) e Vale et al. (2021) utilizaram o azul de metileno com uma concentração de 0,005\%, aplicado sobre a língua por aproximadamente cinco minutos. Já em Gonçalves et al. (2018) os autores realizaram a aPDT com o extrato de bixa orellana (urucum) manipulado na concentração de $20 \%$ e Motta et al. (2021) também utilizou o urucum como fotossensibilizador, porém o autor não descreveu a concentração utilizada do mesmo.

De acordo com os materiais analisados, não existe um único valor de comprimento de onda utilizado na aPDT. Diversos autores usaram o valor de 660nm e isso está relacionado com o fotossensibilizador utilizado no estudo, pois cada um deles tem um espectro de absorção diferente, mudando assim o comprimento de onda do laser utilizado.

3.2.1 Mecanismos de ação da terapia fotodinâmica

A substância fotossensibilizante se liga às células e quando ativada pela luz do laser, produzirá radicais livres de oxigênio, levando a necrose ou apoptose celular dos microrganismos (Gonçalves et al., 2017).

\subsection{Terapia fotodinâmica no tratamento da halitose de origem bucal}

A literatura aborda diversos protocolos de aPDT para tratamento da halitose de origem bucal e trouxemos, na Tabela 1, alguns deles para discussão. 
Tabela 1 - Terapia Fotodinâmica Antimicrobiana no tratamento da halitose de origem bucal.

\begin{tabular}{|c|c|c|}
\hline AUTOR & OBJETIVO & METODOLOGIA \\
\hline $\begin{array}{l}\text { Romero et al } \\
(2021)\end{array}$ & $\begin{array}{l}\text { Verificar se a } \\
\text { mudança no modo de } \\
\text { higiene oral associado } \\
\text { a aPDT ou raspador } \\
\text { de língua pode reduzir } \\
\text { a halitose após } 90 \text { dias } \\
\text { seguidos. }\end{array}$ & $\begin{array}{l}\text { Vinte participantes com halitose positiva foram randomizados para G1 } \\
\text { (grupo experimental: aPDT) e receberam tratamento com aPDT } \\
\text { orientações de higiene bucal (OHB) e vinte indivíduos para G2 (grupo } \\
\text { controle: raspador de língua), nos quais foram tratados com raspador } \\
\text { pelo mesmo operador + sessões de OHB. O protocolo de aPDT ocorreu } \\
\text { da seguinte forma: aplicação de } 0,005 \% \text { de azul de metileno no terço } \\
\text { médio e posterior da parte de trás da língua. Após isso, realizaram uma } \\
\text { pré-irradiação de } 1 \text { minuto. Foi utilizado o laser de diodo vermelho com } \\
\text { as seguintes especificações: } \lambda=660 \text { nm, potência de saída de } 100 \text { mW, } 9 \mathrm{~J} \\
\text { por ponto, fluência de } 318 \mathrm{~J} / \mathrm{cm}^{2} \text { e irradiância de } 3537 \text { mW/cm² com } \\
\text { aplicação pontual e perpendicular para a língua. Além disso, foi } \\
\text { realizado o método de contato direto. As irradiações foram aplicadas em } \\
6 \text { pontos com } 1 \text { cm entre eles. Após isso, para remover completamente o } \\
\text { fotossensibilizador, a língua foi lavada com soro fisiológico. Já a } \\
\text { raspagem de língua foi realizada com o raspador posicionado no dorso } \\
\text { da língua (em seu terço posterior) e tracionado para o terço anterior. O } \\
\text { mesmo foi puxado } 10 \text { vezes no lado direito da língua e } 10 \text { vezes no lado } \\
\text { esquerdo. Além disso, após a utilização do raspador, os participantes } \\
\text { foram orientados a enxaguar a boca com } 10 \text { mL de água e saliva. Após } \\
\text { os tratamentos propostos para o G1 e G2, foram realizadas novas } \\
\text { halitometrias com cromatografia gasosa. Os pacientes foram convidados } \\
\text { a retornar após } 7 \text { e } 90 \text { dias para nova avaliação. Todos os pacientes } \\
\text { incluídos no estudo receberam OHB (orientações sobre o uso do fio } \\
\text { dental e sobre a técnica de Bass para escovação dos dentes). O teste t } \\
\text { pareado foi utilizado para a análise estatística. }\end{array}$ \\
\hline
\end{tabular}

Vale et al Comparar o efeito (2021) da aPDT e raspagem da língua em pessoas idosas com próteses totais com diagnóstico de halitose.
A avaliação da halitose foi feita por meio da cromatografia gasosa imediatamente após a limpeza das próteses com clorexidina $2 \%$ e mucosas bucais com clorexidina $0,12 \%$. Essa avaliação foi realizada após a primeira sessão e após um período de sete dias (segunda sessão). A raspagem lingual foi realizada com raspador de língua posicionado na porção posterior da língua e arrastado na direção anterior em ambos os lados. Após isso, os participantes foram instruídos a enxaguar a boca com $10 \mathrm{~mL}$ de água e saliva. O protocolo de aPDT foi realizado da seguinte maneira: aplicação de azul de metileno $0,005 \%$ em quantidade suficiente para cobrir o terço médio e posterior da língua. Depois de cinco minutos, seis pontos (separados por uma distância de $1 \mathrm{~cm}$ ) foram irradiados com um laser de diodo em contato com a língua utilizando os seguintes parâmetros: $\lambda=660 \mathrm{~nm}$, potência de saída de $100 \mathrm{~mW}$, 9J por ponto, irradiância de 35368 $\mathrm{mW} / \mathrm{cm}^{2}$ com aplicação por contato direto. Após a aPDT, o fotossensibilizador foi removido com uma solução salina abundante. $\mathrm{O}$ desfecho primário deste estudo foi medido com sulfeto de hidrogênio em parte por bilhão (ppb) por meio da cromatografia gasosa. Os desfechos secundários foram os outros dois gases: metanotiol e sulfureto de dimetila medidos em ppb. Além disso, foi realizada análise estatística usando o teste de Shapiro-Wilks, teste t e o teste Kruskal-Wallis Rank.

\section{CONCLUSÃO}

Apenas a aPDT foi capaz de diminuir a halitose a níveis imperceptíveis. 
Labban et al Avaliar a eficácia (2020) da PDT para o tratamento da halitose em termos de análises clínicas e microbianas em idosos usando dentaduras.
Os pacientes foram divididos em dois grupos: pacientes em tratamento com raspador de língua e desinfecção completa da boca (grupo 1) e pacientes em tratamento com raspador de língua, desinfecção bucal total e única aplicação do PDT (grupo 2). A mucosa oral dos indivíduos foi completamente desinfetada com auxílio de gaze estéril embebida em clorexidina $0,12 \%$. A superfície da prótese também foi desinfectada por meio do escalonamento ultrassônico e aplicação de solução de clorexidina a $2 \%$. Os participantes do grupo 1 foram instruídos para realizar a raspagem utilizando um raspador de língua posicionado no terço posterior da superfície dorsal da língua próximo à região das papilas valadas, puxando o mesmo da região posterior ao ápice da língua com pressão. Após realizar esta atividade, os participantes foram convidados a expectorar após enxágue com $50 \mathrm{ml}$ de água por $2 \mathrm{~s}$. Os integrantes do grupo 2 foram submetidos ao seguinte protocolo de aPDT: aplicação de azul de metileno na concentração de $0,005 \%$ na superfície média e dorsal da língua e dentadura por cinco minutos. Usando o método de ponto direto, um laser de diodo de comprimento de onda $660 \mathrm{~nm}$ foi introduzido na língua. A potência radiante média, densidade de energia e radiância foram definidos em $100 \mathrm{~mW}, 3527 \mathrm{~mW} / \mathrm{cm}^{2}$ e $9 \mathrm{~J}$, respectivamente. Um total de seis pontos na língua e 6 pontos na superfície da dentadura foram irradiados com uma distância de $1 \mathrm{~cm}$ entre os respectivos pontos. A avaliação da halitose foi feita com o auxílio de um cromatógrafo gasoso. Já a amostragem microbiana para detecção de Porphyromonas gingivalis ( $\mathrm{P}$. gingivalis) foi realizada do dorso da língua usando um cotonete esterilizado no início e após o tratamento nos dias 5, 15 e 30 e quantificado usando a reação em cadeia da polimerase. A qualidade de vida relacionada à saúde bucal foi avaliada usando a escala Likert de 14 pontos, utilizada no perfil de impacto na saúde bucal.

Gonçalves et Avaliar a presença

Gonçalves et Avaliar a presença al (2017) de halitose em pacientes com Esclerose Múltipla e verificar se o tratamento com aPDT é eficaz contra isso.
Foram selecionados trinta pacientes com Esclerose Múltipla e trinta pacientes, pareado em idade e gênero, como um grupo controle. A avaliação da halitose foi realizada por meio da cromatografia gasosa. Após isso, foi realizado o processo de raspagem com um raspador de língua de plástico. Em seguida, a seguinte técnica de aPDT foi realizada: aplicação de azul de metileno em uma concentração de $0,005 \%$ na língua (terço médio e dorso) por 5 minutos. O excesso foi retirado com o sugador para manter a superfície molhada com o próprio fotossensibilizador, sem o uso de água. Um laser vermelho foi utilizado juntamente com uma ponta cônica para uso em odontologia e um diâmetro de $0,094 \mathrm{~cm}^{2}$. A irradiação foi realizada em seis pontos que tinham $1 \mathrm{~cm}$ de distância entre eles, $\mathrm{O}$ instrumento foi calibrado com um comprimento de onda de 660nm, uma energia de $9 \mathrm{~J}$ e uma
A aPDT contribuiu na diminuição da concentração de sulfeto de hidrogênio e na melhoria da qualidade de vida em pacientes idosos com próteses dentárias.

$\begin{array}{lr}\text { O tratamento da } \\ \text { halitose } & \text { com } \\ \text { raspagem } & \text { lingual } \\ \text { associada a } & \text { aPDT } \\ \text { mostrou-se } & \text { eficaz } \\ \text { nos dois } & \text { grupos } \\ \text { analisados. } & \end{array}$
analisados. 
potência de $100 \mathrm{~mW}$ por 90 s por ponto, uma fluência de 320 $\mathrm{Jcm}^{2}$ e uma irradiância de $3537 \mathrm{~mW} \mathrm{~cm}^{2}$. Foi utilizado o método de aplicação pontual em contato com a língua. Os dados foram analisados usando o teste de Shapiro-Wilk, o teste Mann-Whitney e Wilcoxon, o coeficiente de Spearman, o teste do qui-quadrado, seguido do Teste de G Williams.

Fonte: Romero et al (2021), Vale et al (2021), Labban et al (2020) e Gonçalves et al (2017).

No estudo de Romero et al. (2021) é provável que o tempo de acompanhamento (90 dias) tenha interferido nos resultados, uma vez que, após alguns dias da aPDT, a superfície da língua é recolonizada por bactérias anaeróbias gram negativas, que serão responsáveis pela degradação proteolítica e liberação de compostos de enxofre voláteis, retornando assim, ao quadro de halitose bucal. Além disso, apesar do trabalho de Vale et al. (2021) ter sido semelhante ao de Romero et al. (2021), não é citado nele o tempo de acompanhamento após a realização da aPDT, o que pode ter causado a diferença nos resultados alcançados. Ademais, como o estudo foi realizado com pacientes idosos, existe um risco de viés devido às possíveis limitações no ato de raspagem da língua, qualidade e higienização das próteses.

No trabalho de Labban et al. (2020), após 30 dias, o efeito da aPDT ainda estava presente. A possível razão pode ser atribuída a aplicação da aPDT na superfície da língua e da prótese total. Além disso, pacientes edêntulos totais apresentam um número reduzido de superfícies intrabucais, nas quais as bactérias podem agregar-se. Portanto, houve uma maior redução microbiana após a realização do protocolo proposto, diminuindo assim, os níveis de halitose bucal. A melhoria na qualidade de vida foi avaliada por meio de uma pesquisa de opinião (escala Likert), na qual os integrantes do grupo 2 apresentaram pontuações significativamente mais baixas em comparação ao grupo 1, corroborando assim, com a melhoria na qualidade de vida relacionada à saúde bucal.

Na pesquisa de Gonçalves et al. (2017), o fato de os resultados terem sido satisfatórios em ambos os grupos pode estar relacionado com a realização de raspagem e aPDT juntas, removendo assim, as bactérias que produzem compostos de enxofre voláteis de maneira mais eficaz. Porém, o estudo apresenta alguns riscos de viés por não abordar o tempo de acompanhamento e apresentar um número limitado de participantes que retornaram para reavaliação.

Por fim, as metodologias utilizadas nos ensaios clínicos citados na tabela 1 foram diferentes. Diante disso, existe uma grande possibilidade de a diferença nos resultados serem decorrentes da realização de protocolos distintos. Além disso, Ciarcia et al (2019) sugerem que a inclusão de novas alternativas de tratamento para a halitose possa melhorar a experiência dos pacientes em relação aos resultados.

\section{Considerações Finais}

A aPDT mostrou-se eficaz na redução do sulfeto de hidrogênio imediatamente após sua aplicação, reduzindo a halitose de origem bucal, em um curto período de tempo.

O fotossensibilizante é ativado pela luz do laser, se ligando às células e produzindo radicais livres de oxigênio. Como consequência, ocorre a morte programada dos microrganismos responsáveis pela produção de compostos de enxofre voláteis.

Diante disso, torna-se importante a realização de artigos e trabalhos futuros que abordem o uso da aPDT no tratamento da halitose origem bucal. 


\section{Referências}

Aguiar, M C A D, Pinheiro, N C G, Marcelino, K P, \& Lima, K C D (2017). Halitose e fatores associados em idosos institucionalizados. Revista Brasileira de Geriatria e Gerontologia , 20 , 856-868.

Bicak, DA (2018). Uma abordagem atual para a halitose e o mau hálito oral-A mini revisão. The open dentistry journal , 12 , 322.

Costacurta, M., Petrini, M., Biferi, V., Arcuri, C., Spoto, G., Brescia, A., \& Docimo, R. (2020). Prótese dentária e halitose: Avaliação do mau hálito em pacientes com e sem prótese dentária. Journal of Osseointegration , 12 (4), 730-735.

da Mota Ciarcia, A. C. C., Gonçalves, M. L. L., Horliana, A. C. R. T., Suguimoto, E. S. A., Araujo, L., Laselva, A., ... \& Bussadori, S. K. (2019). Action of antimicrobial photodynamic therapy with red leds in microorganisms related to halitose: Controlled and randomized clinical trial. Medicine, $98(1)$.

do Vale, K L, Horliana, AC R T, Dos Santos, S R, Schalch, T O, de Ana, A M, Ferrari, R A M, ... \& Fernandes, KPS (2021). Tratamento da halitose com terapia fotodinâmica em idosos com próteses totais: um ensaio clínico randomizado e controlado. Photodiagnosis and Photodynamic Therapy, 33 , 102128.

do Vale, K L, Horliana, A CR T, dos Santos Romero, S., de Melo Deana, A., Gonçalves, MLL, Ferrari, RAM, ... \& Fernandes, KPS (2019). Avaliação do tratamento da halitose com terapia fotodinâmica em pacientes idosos com prótese total: protocolo para um ensaio clínico randomizado e controlado. Medicine, 98 (27).

Du, M., Li, L., Jiang, H., Zheng, Y., \& Zhang, J. (2019). Prevalência e fatores relevantes da halitose em indivíduos chineses: uma pesquisa clínica. BMC saúde oral, $19(1), 1-11$.

Giafferis, R. B. L., Junior, L. A. V. S., da Silva Santos, P. S., \& Chicrala, G. M. (2017). Estratégias terapêuticas disponíveis para xerostomia e hipossalivação em pacientes irradiados de cabeça e pescoço: manual para profissionais da saúde. Revista Uninga, 54(1).

Gonçalves, M L L, Bussadori, SK, Fragoso, Y D, da Silva, V V B, Deana, A M, da Mota, A C C, ... \& França, C M (2017). Efeito da terapia fotodinâmica na redução da halitose em pacientes com esclerose múltipla: ensaio clínico. Journal of breath research, 11 (4), 046006.

Hampelska, K., Jaworska, M M, Babalska, Z. Ł., \& Karpiński, T M (2020). O papel da microbiota oral na halitose intra-oral. Journal of Clinical Medicine, 9 (8), 2484.

Kellesarian, S V, Qayyum, F., De Freitas, P C, Akram, Z., \& Javed, F. (2017). A terapia fotodinâmica antimicrobiana é um protocolo terapêutico útil para a descontaminação oral? Uma revisão sistemática e meta-análise. Fotodiagnóstico e terapia fotodinâmica , 20, 55-61..

Kolbe, A. C., \& Silva, F. L. (2017). Uso da isotretinoína no tratamento da acne e sua relação com a halitose. Revista de Ciências Médicas e Biológicas, 16(1), 101-105.

Mylona, Valina et al. Laser-Assisted aPDT Protocols in Randomized Controlled Clinical Trials in Dentistry: A Systematic Review. Dentistry Journal, v. 8, n. 3, p. 107, 2020.

Mubayrik, A B, Al Hamdan, R., Al Hadlaq, E M, AlBagieh, H., AlAhmed, D., Jaddoh, H., ... e Shryei, RA (2017). Autopercepção, conhecimento e consciência da halitose entre universitárias. Odontologia clínica, cosmética e experimental , 9 , 45.

Nagraj, S K, Eachempati, P., Uma, E., Singh, V P, Ismail, N M, \& Varghese, E. (2019). Intervenções para o manejo da halitose. Cochrane Database of Systematic Reviews , (12).

Patil, S., Acharya, S., Hathiwala, S., Singhal, DK, Srinivasan, SR, \& Khatri, S. (2017). Avaliação da eficácia do G32 (preparação ayurvédica disponível comercialmente) na redução da halitose - Um ensaio clínico randomizado. Jornal de pesquisa clínica e diagnóstica: JCDR, 11 (9), ZC79.

Pereira, A. S., Shitsuka, D. M., Parreira, F. J., \& Shitsuka, R. (2018). Metodologia da pesquisa científica.

Renvert, S., Noack, M J, Lequart, C., Roldán, S., \& Laine, M L (2020). O problema subestimado da halitose intra-oral na prática odontológica: uma revisão de consenso de especialistas. Clinical, Cosmetic and Investigational Dentistry, $12,251$.

Ricci Donato, HA, Pratavieira, S., Grecco, C., Brugnera-Junior, A., Bagnato, V S, \& Kurachi, C. (2017). Comparação clínica de dois fotossensibilizadores para descontaminação da cavidade oral. Fotomedicina e cirurgia a laser , 35 (2), 105-110.

Romero, S S, do Vale, K L, Remolina, VG, Silva, T G, Schalch, T O, Ramalho, K M, ... \& Horliana, ACRT (2021). Higiene oral associada à terapia fotodinâmica antimicrobiana ou raspador lingual na redução da halitose após 90 dias de acompanhamento: Um estudo randomizado, controlado, únicocego. Photodiagnosis and Photodynamic Therapy, 33 , 102057.

Seerangaiyan, K., Jüch, F., \& Winkel, EG (2018). Revestimento da língua: suas características e papel na halitose intra-oral e saúde geral - uma revisão. Journal of breath research, 12 (3), 034001.

Silva, MF, Leite, F R, Ferreira, L B, Pola, N M, Scannapieco, F A, Demarco, F F, \& Nascimento, G G (2018). Prevalência estimada de halitose: uma revisão sistemática e análise de meta-regressão. Investigações clínicas orais , 22 (1), 47-55

Tungare, S., Zafar, N., \& Paranjpe, A. G. (2018). Halitosis.

Veloso, Dejanildo J. et al. Potential antibacterial and anti-halitosis activity of medicinal plants against oral bacteria. Archives of oral biology, v. 110, p. $104585,2020$.

Wang, J., \& He, L. (2017). Efeito da autolimpeza mecânica da saburra lingual sobre o mau odor em pacientes com halitose originada da saburra lingual. Pequim da xue xue bao. Yi xue ban = Journal of Peking University. Ciências da Saúde , 49 (2), 344-348. 